UCRL-ID-124079

\title{
A Micromachined Chemical Jet Dispenser
}

\section{S. Swierkowski}

D. Ciarlo

May 13, 1996

This is an informal report intended primarily for internal or limited external distribution. The opinions and conclusions stated are those of the author and may or may not be those of the Laboratory.

Work performed under the auspices of the U.S. Department of Energy by the Lawrence Livermore National Laboratory under Contract W-7405-Eng-48. 


\section{DISCLAIMER}

This document was prepared as an account of work sponsored by an agency of the United States Government. Neither the United States Government nor the University of California nor any of their employees, makes any warranty, express or implied, or assumes any legal liability or responsibility for the accuracy, completeness, or usefulness of any information, apparatus, product, or process disclosed, or represents that its use would not infringe privately owned rights. Reference herein to any specific commercial product, process, or service by trade name, trademark, manufacturer, or otherwise, does not necessarily constitute or imply its endorsement, recommendation, or favoring by the United States Government or the University of California. The views and opinions of authors expressed herein do not necessarily state or reflect those of the United States Government or the University of California, and shall not be used for advertising or product endorsement purposes.

This report has been reproduced directly from the best available copy.

Available to DOE and DOE contractors from the Office of Scientific and Technical Information

P.O. Box 62, Oak Ridge, TN 37831

Prices available from (615) 576-8401, FTS 626-8401

Available to the public from the

National Technical Information Service

U.S. Department of Commerce 5285 Port Royal Rd.,

Springfield, VA 22161 
UCRL-ID-124079

\title{
A Micromachined Chemical Jet Dispenser
}

\author{
Principal Investigator: Steve Swierkowski \\ Co-Investigator: Dino Ciarlo
}

May 13, 1996

Lawrence Livermore National Laboratory

Laboratory Directed Research \& Development Project 95-LW-108 


\title{
A Micromachined Chemical Jet Dispenser
}

\author{
Principal Investigator: Steve Swierkowski \\ Co-Investigator: Dino Ciarlo
}

\section{Objective}

The goal of this project is to design, build, and test a new type of microstructure that is a multichannel micromachined chemical fluid jet dispenser that is applicable to prototype tests with biological samples that demonstrate its utility for molecular biology experiments. The objective is to demonstrate a new device capable of ultrasonically ejecting droplets from 10-200 $\mu \mathrm{m}$ diameter capillaries that are arranged in an array that is linear or focused.

\section{Background}

The greatest application to date of MEMS(Micro Electro Mechanical Systems) technology is the extremely successful computer printer ink jet print head, which is a silicon based microstructure based on the heated bubble jet concept. Many applications exist for a highly improved method of dispensing miniature chemical droplets where heating is not allowed, and new opportunities will arise, in the fields of molecular biology, clinical labs, environmental labs, and the chemical industry. It will replace, speed-up, and decrease the sample sizes being handled in many chemistry processing sequences, particularly those involved with manual or even current robotic pipetting procedures. The chemical jet samples can be rapidly dispensed precisely in location, size, and time under computer control. Miniaturized chemical experiments by the thousands can be rapidly done with this device; this is amenable to multiple processes requiring many combinatorial and/or sequential chemical reactants to be combined or just placed, separately or jointly, for subsequent processing or analysis. For example, the human genome program has ideal applications for this proposed dispenser; the arraying of transformed bacterial colonies carrying DNA of chromosome 19 onto $8 \times 12 \mathrm{~cm}$ nylon filters is a significant bottleneck (currently $>3$ hours for 45 nylon filters) to the research as it is currently done with a slow robotic needle dipping method. Other biomedical applications include synthesis of DNA oligomers, and injection into multichannel electrophoresis experiments. The potential exists to lower the dispenser production costs so that instrumentation could be disposed of rather than cleaned and re-used, which is a big advantage for infectious or toxic materials; smaller samples can be handled, thus producing less chemical usage and waste. Enormously advantageous scaling factors accrue by reducing the sample diameter, L:

Concentration(fixed solute) $\propto \mathrm{L}^{-3}$, Time(diffusion) $\propto \mathrm{L}^{+2}$, Density (spatial array) $\propto \mathrm{L}^{-1}$.

\section{Device Concept}

The prototype device of this project is based on several common fabrication procedures used in MEMS technology. First, standard spin coated positive photoresists(PR) and contact lithography from standard $100 \mathrm{~mm}(4 \mathrm{x} 4 \mathrm{inch})$ photomasks is used. The preferential etching of [100] oriented silicon that is double side polished, is used to form the fluid reservoirs in this microfluidics device; these reservoirs are referred to as the dead well and driven well. The preferential etching of the silicon leaves a square well in the silicon with a very thin $(40 \mu \mathrm{m})$ membrane of silicon left. The 
silicon membrane of the driven well is actuated by a bonded piezoelectric transducer that deflects the membrane inward, compresses the fluid in the driven well, and ejects a micro droplet out the exit nozzle. The piezoelectric transducer is mounted with conductive epoxy to gold pads that are evaporated onto the silicon opposite the etched wells, on the outside of the silicon wafer; extra metal is deposited for contacts and other alignment features to be discussed later. The micro capillaries connecting the reservoirs to the inlet and exit nozzle are etched in Pyrex glass. This $1 \mathrm{~mm}$ thick glass is anodically bonded to the standard thickness $(375 \mu \mathrm{m})$ silicon wafer. This anodic bonding method is well established and known to sustain pressures in excess of $1.4 \mathrm{MPa}$ (200 psi). Most of the fabrication is of the type used in the MEMS or IC industry and yields a precision integrated structure. The piezoelectric actuator was chosen for its high pressure, small displacement attributes as well as its commercial availability in high quality, thin plate form. Piezoelectric thin films integrated onto the microfluidics structure were considered, but it was deemed to be an immature technology at this point; it is questionable if thick enough, high quality films could be produced by this method, and it would also be a major processing investment and development. Commercial PZT(lead zirconium titanate) plates, that were plated and poled were used to make a bimorphic actuator. A sketch of the device concept is shown in Figure 3.1. The actual prototype device had parallel rather than converging exit nozzles. It also had a small glass support layer bonded onto the dead well, to prevent this well's membrane from bursting in operation; this support layer is not shown in the sketch.



Figure 3.1. Concept sketch of chemical jet dispenser composed of bonded silicon and glass wafers. A micro chemical droplet is ejected from the exit nozzle by pressure generated by a piezoelectric driver. 
This micro-jet dispenser can test several new concepts: 1 . orifice/capillary in the plane of the silicon wafer; the common ink jet dispensers use an exit nozzle or orifice perpendicular to the plane of the silicon wafer, usually on the wall of the driven well. 2. an innovative fluid compliance feature using a contamination and leak proof capacitive dead well under a flexible silicon diaphragm; 3 . integrated ultrasonic drive - highly efficient through a thin silicon membrane window that does not heat the fluid; 4. ultrasonic channel -to-channel isolation through an orthogonal layout geometry.

Some of the research issues to address are related to operational principles and the magnitude of various physical effects; these include: 1. ultrasonic cross talk, 2. droplet precision, 3. nozzle drying, 4. hydraulic resistance and compliance for different fluids and droplet repetition rate, 5. integration of piezoelectric drivers and the minimum size drive needed, 6. capillary blockage by particulates, and 7. fluid feed pressure control.

\section{Device Fabrication}

\section{Masks and Overview}

Fairly complete full scale sketches of the first two layers for the silicon are shown in Figure 4.1.

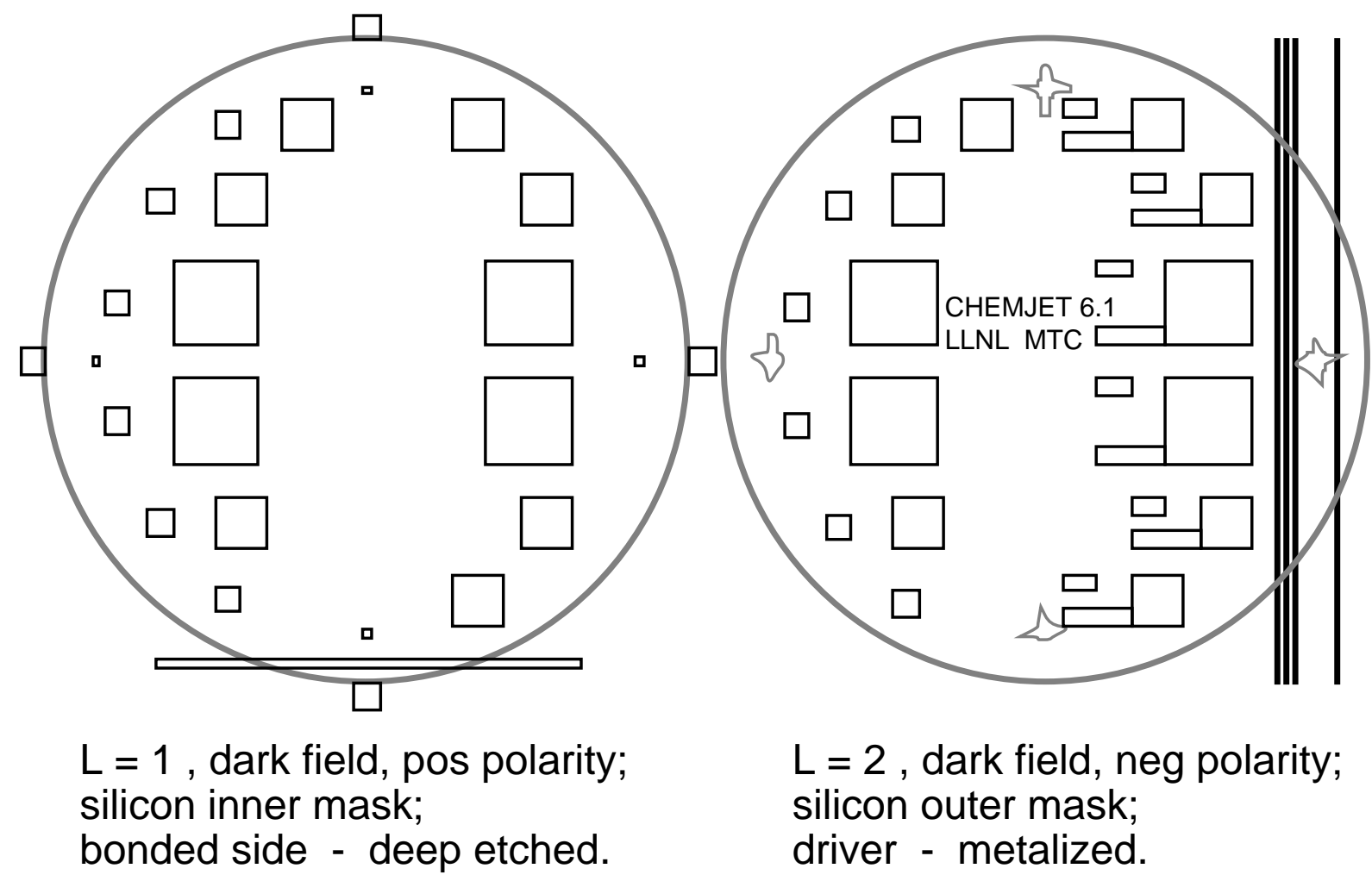

Figure 4.1. Photomask layers 1 and 2 full scale; the reference circle is the outline of the silicon wafer (75 $\mathrm{mm}$ diameter, [3 inch]).

The prototype device was fabricated with the use of three photolithographic masking layers: 1.) the first layer is used to pattern the silicon on the inside or bonded side with a deep timed etch to make the fluid wells and actuator diaphragm in the silicon, 2.) the second layer is to pattern a gold layer 
onto the outer silicon and it is registered with the first layer, and 3.) the third layer is used to define the six capillaries, and each has varying diameters from the feed section(large $\sim 400 \mu \mathrm{m}$ ), to the middle section( small $\sim 20 \mu \mathrm{m}$ ), to the nozzle section( medium $\sim 100 \mu \mathrm{m}$ ).

Not all the alignment features show up in Figure 4.1. There are some too small to print and some large ones on the corners of the mask that are not shown that enable aligning the two masks together in a two sided alignment jig, prior to wafer insertion and clamping. The large baseline feature in layer one is used to align the mask to the wafer flat, so that the anisotropic etching is aligned with the [010] and [001] axes. The outer squares are gross alignment features to find the edge of the wafer for centering. In layer two, the metalized outer layer, the large vertical lines are for eventually marking the precision wafer saw cut lines, used to form the end of the exit nozzles. The other features in layer two are there for location and alignment of the entry holes and the dead well and the driven well and to provide a conductive base with contact for mounting the PZT actuator.

The third layer is used for patterning the capillaries into the glass. This layer is shown in Figure 4.2 along with a composite drawing showing the overall device in plan view after the PZT has been added to the gold on silicon pads and the assembly has been cut along the plane defining the end of the exit nozzles.

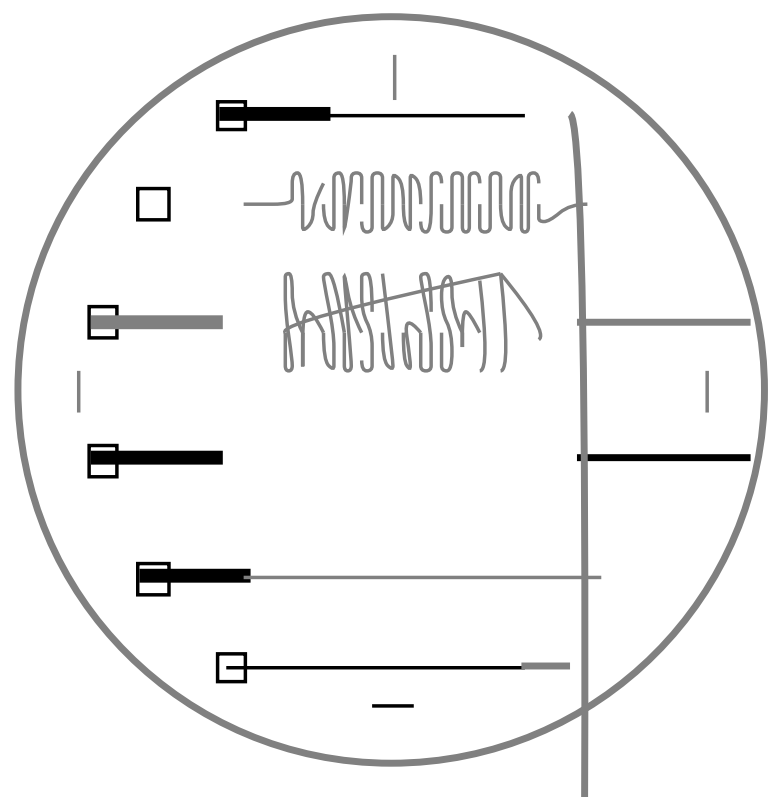

$\mathrm{L}=3$, dark field, pos polarity; glass inner mask -bonded side; Large(left), small(mid.), medium(rt.) capillaries etched.



$\mathrm{L}=2 \& 3$, device composite; silicon top view; PZT cross hatched; nozzle exits cut.

Figure 4.2. The layer three is used to define the six capillaries in the glass substrate; the reference circle is the outline of the silicon wafer $(75 \mathrm{~mm}$ diameter, [3 inch]). Each capillary has varying diameters according to function. The supply section is large and short; the flow restriction section is small and long, sometimes meandering; and the exit region is medium sized and short. The right sketch is a composite view of the finished device, but without the fluid inlet tubes that will be epoxy bonded to the inlet ports, shown as small squares on the left side. 


\section{Silicon Processing}

The silicon starting material is [100] oriented with standard wafer flats and is double side polished and $375 \mu \mathrm{m}$ thick. The following is a brief outline of the fabrication sequence for the silicon part of the device.

SILICON PROCESS SEQUENCE:

1. Clean the silicon wafers - RCA clean.

2. CVD deposit masking nitride. $100 \mathrm{~nm}$ low stress silicon nitride.

3. Coat with HMDS adhesion promoter.

4. Print layer one; the silicon well patterns. Shipley 1518 positive resist, $1 \mu \mathrm{m}$ thick.

5. Plasma etch layer one features into silicon nitride(etch windows); $\mathrm{CF}_{4} / \mathrm{O}_{2} / 200 \mathrm{mT} / 150 \mathrm{~W}$.

6. Timed $\mathrm{KOH}$ etch of silicon to form reservoirs and actuator membranes and inlet ports. Done in three steps with intermediate depth measurements to estimate finish time when silicon membrane is $40 \mu \mathrm{m}$ thick.

7. Strip the remaining silicon nitride mask.

8. Coat with HMDS adhesion promoter.

9. Spin coat with Shipley 1518 positive resist, $1 \mu \mathrm{m}$ thick, in special spinning jig with retaining pins around the periphery, not using vacuum clamp because of the membranes. Soft bake.

10. Use special double sided alignment jig: align layer two mask to layer one mask in jig.

11. Print layer two: align wafer etched features from layer one to layer one mask; assemble prealigned jig and print layer two. When drying wafers after development and rinse, use special care with air drying nozzle; use at low pressures and angle shallow enough to prevent blowing Si windows in, or creating a Bernoulli effect and sucking them out.

12. Ebeam evaporate layer two metals for outside locators(inlet ports, dead wells, and wafer precision saw lines, and PZT pads): $10 \mathrm{~nm} \mathrm{Cr}$ then $100 \mathrm{~nm} \mathrm{Au}$.

13. Liftoff in hot acetone and ultrasonic. Use Q tip in hot(boiling) acetone to scrub the metal that is not "lifted off", but very carefully avoid the silicon membranes. The e-beam coater tends to overheat the photoresist, impeding lift off.

14. Rinse in isopropyl alcohol and water. Blow dry.

\section{Glass Processing}

The glass for the device is the Corning 7740 type, commonly known as Pyrex. This glass is designed to have a similar thermal expansion coefficient to the silicon and is also useful for anodic bonding. The glass wafers used for this project were double side polished by an optical supplier to an optical finish from the manufacturer's blanks; the original thickness was about $3 \mathrm{~mm}$ and the final size is $1 \mathrm{~mm}$ thick and $75 \mathrm{~mm}$ in diameter.

GLASS PROCESS SEQUENCE:

1. Clean the glass wafers; organic removal: hot peroxide/sulfuric; water rinse.

2. Sputter coat the glass, capillary side, with $100 \mathrm{~nm}$ Mo at low power(low stress).

3. Print layer three; the capillaries.

4. Etch the capillary patterns into the $\mathrm{Mo} ; 35 \mathrm{H}_{3} \mathrm{PO}_{4} / 35 \mathrm{H}_{2} \mathrm{O} / 20 \mathrm{Acetic} / 10 \mathrm{HNO}_{3}$.

5. Strip the photoresist.

6. Etch the capillaries into the glass; $40 \mathrm{HF} / 40 \mathrm{HCl} / 20 \mathrm{H}_{2} 0$; patterned Mo mask.

7. Strip the Mo.

8. Water rinse, blow dry. 


\section{Piezoelectric Processing}

The piezoelectric actuator is made from commercial PZT(Lead Zirconium Titanate) plates that are silver plated and poled; the plates are $225 \mu \mathrm{m}$ thick and $25 \mathrm{~mm}$ square.

\section{PZT PROCESS SEQUENCE:}

1. First, the poling polarity must be determined. This is easily done by placing the PZT plate on a simple jig made with an aluminum foil covered microscope slide and a spring contact. The bottom side of the plate contacts the foil which is used as electrical ground. The top side of plate is contacted by a spring contact that is connected to an oscilloscope. With the oscilloscope scanning at about a one second rate and a vertical sensitivity of about $0.1 \mathrm{~V} / \mathrm{cm}$, the plate is mechanically tapped gently with a small tool, such as a rounded cap end of a ball point pen. The PZT is very fragile and prone to cracking if sharp tools, or deforming forces are used. The compressive force of the tool impact generates a bipolar pulse whose initial portion is positive when the top side is oriented correctly; this side is then marked positive.

2. The PZT bimorph can be formed by bonding together two PZT plates with opposing poling polarities, either head to head or tail to tail. Either method can work, but the bending motion (a dome like bulge of the bimorph plate) from an applied field will have opposing polarities, so it is very important to keep track of the polarities throughout. The bonding is accomplished using silver conductive epoxy, spread onto the plates with a wooden toothpick to several hundred microns thick. The two plates are then brought into contact. The excess epoxy is initially squeezed out by hand pressure, starting at the center, and then removed with a Q tip; the plate pair is finally pressured between to glass plates that are covered with wax paper and squeezed again with hand pressure of several pounds force. A curing weight of about $600 \mathrm{~g}$ is applied to composite plate stack. This results in an epoxy bond layer about $100 \mu \mathrm{m}$ thick.

3. The bonded plates are now shorted on the sides by the excess epoxy. The square actuators and test cantilever beams are cut from the bonded pair with a precision abrasive saw that is water cooled. The edges of the bimorph are now clean and free from any silver or epoxy that might short out the device. These edges must be kept clean and free from fingerprints, etc., to prevent arc formation from high bias voltages.

4. The polarity of the bonded pair is determined before edge sealing and mounting onto the anodically bonded silicon/glass composite. The bonded pair test is also determined with a very simple, but different clamping jig. This jig is again made with an aluminum foil covered microscope slide. The PZT bimorph is placed on the slide so that about $1.5 \mathrm{~mm}$ of it is off the end of the foil, but still over the glass. This portion is then clamped with a small alligator clip, bent so that it contacts the upper bimorph electrode; the lower bimorph electrode is contacted by the aluminum foil at its edge. This leaves the entire bimorph, mounted like a diving board, tilting slightly off but still over the foil covered slide. See Figure 5.3. The free end, opposite the alligator clip clamp, is placed under a microscope. By applying voltages from ten to several hundred volts across the bimorph, the end of the device deflects under the microscope. With a high magnification, the depth of field is very shallow, and the vertical position of the free end of the bimorph can be determined as a function of voltage. The polarity of the composite is again marked with a pencil on the silver plating, so that it is clear which side of the composite must have a certain polarity voltage in order to deform in a convex fashion.

5. The sides of the bimorph are now coated with a thin layer of clear, non conductive epoxy. This is done by first generating some of the epoxy in a very thin layer on a microscope slide, using another slide as a squeegee. Then the bimorph is held by a small vacuum chuck and contacted into the thin layer, edge-on, sequentially on all four sides. After the clear epoxy is placed on all four edges, the bimorph is pressed against a wax paper protected glass plate. This last procedure should leave the mounting side of the bimorph flat, so that its silver plating 
can be bonded to the gold plated silicon pad; the sides should be well protected from shorting out in the final conductive epoxy mounting procedure to the silicon and also protected from shorting out or arcing along the edges of the bimorph. One final deflection and polarity check is done to confirm the absence of shorts and correct polarity.

\section{Bonding and Final Assembly}

1. The silicon and glass wafers are anodically bonding together at $450^{\circ} \mathrm{C}$ in an nitrogen atmosphere. First, alignment is done under a low power microscope by hand and pressure is applied until interference fringes are observed. With a successful anodic bond, the silicon actuator diaphragms are visibly bowed inwards about $100 \mu \mathrm{m}$ by the atmospheric pressure during the cool down. The entire capillary system and fluid cavities are under partial vacuum and a leak free channel is obvious. The yield for this procedure was $100 \%$ for about six wafer pairs with six channels per wafer. The inlet port is now opened by forcing a syringe tip into the silicon membrane in the inlet port region; the hole is enlarged using the beveled edge of the syringe tip. The debris is lightly shaken loose, but the excess small silicon debris is not blown off or washed out at this stage to prevent it from jamming in the inlet capillary. The composite wafer pair is now cut on a water cooled precision wafer saw to form the exit nozzles; the gold reference cut lines on outer silicon side are used for saw alignment. The robust glass outer bottom side is used for adhesive mounting to the saw table. After the sawing, the wafer composite is ultrasonically washed in water and isopropyl alcohol to remove saw and silicon debris from the previous steps. The alcohol is finally removed from the interior of the device by placing it at an approximately 30 degree incline under an incandescent desk lamp to proved a slow drying situation with a modest temperature and gravimetric gradient.

2. The PZT bimorph is bonded onto the silicon side of the silicon/glass wafer pair with silver conductive epoxy. A vacuum chuck is used. The bimorph is pressed and laterally moved very slightly to thin the conductive epoxy; it is very important to get the epoxy thin for good transducer coupling, while not shorting out the insulating protective side walls of the bimorph. At the same time, small electrical leads can be epoxied onto the bimorph ground plane pad and also onto the top of the bimorph, using a minimal mass.

3. The dead wells are capped on the outside with clear epoxy using $12 \mathrm{~mm}$ square pieces of glass. This is to protect the dead well from bursting during priming/purging operations.

4. The inlet to the wafer pair is done with standard syringe needle where the end has been filed to a very blunt bevel, with the opening facing the channel. The needle is supported by an aluminum cylindrical ferrule, with a loose sliding fit over the needle. The inlet connection takes three sequential epoxy joints. First, the ferrule is coated with a very small amount of epoxy on its outer cylindrical edge, near the bottom, but not at all on the bottom itself. If epoxy is on the bottom face of the ferrule, it will ooze into the inlet port and block it. The ferrule is slid high onto the needle, then the needle is put into the inlet port on the wafer, then the ferrule is released to slide down the needle and make contact with the wafer. The epoxy will make a small fillet on the outside of the cylinder as the ferrule is rotated, while the needle is used to position the assembly. After the ferrule epoxy is cured, the needle can be epoxied onto the top of the ferrule. Finally, a third coating of epoxy can be applied to both joints as a thick supportive layer, now that the parts are sealed and in the correct placement. 


\section{Piezoelectric Theory and Measurements}

\section{Introduction and approximations}

The term "piezoelectric" literally means pressure electricity. This is the direct effect where an applied mechanical stress results in induced electric fields in the piezoelectric material. In this device, the inverse effect is used, where an applied electric field will induce mechanical stresses, and strains, in the materials. It is important to note that piezoelectric materials lack a center of inversion and that a applied field in one direction can induce stresses and strains in multiple other directions. The piezoelectric effect exists in both single crystals, such as quartz, and in polycrystalline material, such as the PZT(Lead Zirconium Titanate), used in this device. The fundamental piezoelectric relations can have many forms, depending upon which variables are chosen as independent and whether the effect is characterized by polarization or electric flux density. Standard engineering compact tensor notation is used; in this scheme, for example, $\mathrm{d}_{333}=\mathrm{d} 33$ and $\mathrm{d}_{311}=\mathrm{d} 31$. The compaction scheme is described in Nye[1] and relies upon the symmetry relations for real materials; for example: $\mathrm{d}_{\mathrm{kij}}=\mathrm{d}_{\mathrm{kji}}$. Subscript compaction is done with the following standard scheme:

\begin{tabular}{|c|c|}
\hline $\mathbf{i j}$ & compact \\
\hline \hline 11 & 1 \\
\hline 22 & 2 \\
\hline 33 & 3 \\
\hline 23 or 32 & 4 \\
\hline 13 or 31 & 5 \\
\hline 12 or 21 & 6 \\
\hline
\end{tabular}

Table 5.1. Compact engineering tensor notation.

The electric flux density scheme with mechanical stress, $\mathrm{T}_{\mathrm{kl}}$, and electric field, $\mathrm{E}_{\mathrm{k}}$, are used as the independent variables in this work:

$$
S_{i j}=s_{i j k l} T_{k l}+d_{k i j} E_{k}
$$

Where $S_{i j}$ is the mechanical strain, sijkl are the elastic compliance constants(the inverse of the elastic stiffness constants or loosely Young's moduli, Ey), and $\mathrm{d}_{\mathrm{kij}}$ are the piezoelectric constants. For the PZT used in this work, type LTZ-2, the manufacturer's specifications for the non-zero constants are[2]:

$$
\begin{aligned}
& \mathrm{d}_{31}=-1.79 \mathrm{E}-10 \mathrm{M} / \mathrm{V} \\
& \mathrm{d} 33=+4.05 \mathrm{E}-10 \mathrm{M} / \mathrm{V} \\
& \text { Ey11 }=+6.10 \mathrm{E}+10 \mathrm{~N} / \mathrm{m}^{2} \\
& \text { Ey22 }=+6.10 \mathrm{E}+10 \mathrm{~N} / \mathrm{m}^{2} \\
& \text { Ey33 }=+5.32 \mathrm{E}+10 \mathrm{~N} / \mathrm{m}^{2}
\end{aligned}
$$

The poling axis is assumed to be the " 3 " direction, i.e. $\mathrm{x} 3=\mathrm{z}$ axis. 
10.

Free standing plates of PZT are illustrated in Figure 5.1, which also shows the principle behind the PZT bimorph used in this project.



Figure 5.1. The PZT bimorph is made by bonding two free plates of oppositely poled material. Plate (a.) is shown as unbiased in the dashed line; when biased, it expands laterally and shrinks vertically. Plate (b.) is similar in size and poling direction, shown by the " $Z$ " axis, but with an opposite polarity bias, and a subsequent lateral shrinkage. The bimorph is made by bonding the two plates together; this is done by inverting the (b.) plate before bonding, so that the poling axes are head to head. The composite is shown in bimorph (c.) where the applied bias fields are now in the same direction and additive. In this configuration, only the two outer electrodes are needed and the inner electrode is allowed to float to an intermediate potential. The elongation of the upper plate and the shrinkage of the lower plate leads to the dome like deformation of the bimorph plates, or the simple bending of slender cantilever.

For a free standing plate of PZT, with the $\mathrm{z}$ axis normal to the plate and an electric field applied along the $\mathrm{z}$ axis, the following relations apply:

$$
\mathrm{S}_{3}=\mathrm{d} 33 \mathrm{E} 3
$$




$$
\mathrm{S}_{1}=\mathrm{S}_{2}=\mathrm{d}_{31} \mathrm{E}_{3}
$$

Some of the transducer plates used in this work are $200 \mu \mathrm{m}$ thick and $12 \mathrm{~mm}$ square. For a single free standing plate of this size, a bias of $100 \mathrm{~V}$ will induce the following deformations:

$$
\begin{aligned}
& \Delta \mathrm{z}=\left(\mathrm{S}_{3}\right) \mathrm{z}=(-2 \mathrm{E}-4) 200 \mu \mathrm{m}=-0.04 \mu \mathrm{m} \\
& \Delta \mathrm{x}=\Delta \mathrm{y}=\left(\mathrm{S}_{1}\right) \mathrm{x}=(+0.9 \mathrm{E}-4) 12 \mathrm{~mm}=+1.08 \mu \mathrm{m}
\end{aligned}
$$

These are small deformations, but they can yield very large stresses, depending upon the boundary conditions that may be applied, as subsequent experiments will show.

The deformation of the high aspect ratio cantilever bimorph or the square bimorph plate is relatively complex, but some simple approximations are useful for initial order of magnitude estimates and design purposes. More exact plate deformation theory will be used later to compare to some of the experimental results. The actual deformations have dominant parabolic and quadratic terms, but some initial estimates will use the deformation modeled by a simple circular arc and are quite useful. The first order of importance is to estimate the volume of fluid displaced by a device membrane deflection and the approximate strain consistent with this. The actual membrane is square $(\mathrm{L} \mathrm{x} \mathrm{L)}$, and it may be approximated by an equal area circular one with diameter, $\mathrm{d}$.

$$
\mathrm{L}^{2}=\left(\pi \mathrm{d}^{2}\right) / 4
$$

The spherical deformation can considered as a spherical segment volume, $\mathrm{V}$, with chord, $\mathrm{d}$, and membrane deflection height, h:

$$
V=\left(\pi h^{2}\right)\left(\left\{\left[d^{2}+4 h^{2}\right] / 8 h\right\}-h / 3\right)
$$

For $\mathrm{d}>\mathrm{h}$, equation 5.8 may be approximated by:

$$
\mathrm{V}=(\pi \mathrm{h})\left(\mathrm{d}^{2} / 8\right)
$$

Using equation 5.7 in 5.9 results in a useful approximation for the fluid displacement, $\mathrm{V}_{\mathrm{f}}$, in the transducer driven well ( $\mathrm{L}$ x L), resulting from a deflection, h:

$$
\mathrm{V}_{\mathrm{f}}=0.5 \mathrm{hL}^{2}
$$

For some typical realistic design numbers, a deflection of $\mathrm{h}=2 \mu \mathrm{m}$, and a side $\mathrm{L}=1 \mathrm{~cm}$, results in a driven well displacement of $\mathrm{V}_{\mathrm{f}}=1 \mathrm{E}+8 \mu \mathrm{m}^{3}=0.1 \mathrm{~mm}^{3}$. For purposes of visualization, it may be useful to note that $1 \mathrm{~mm}^{3}=1 \mu$ litre, or about the size of grain of salt. The $2 \mu \mathrm{m}$ deflection is small; it represents about 2 percent of the diameter of a human hair. A spherical droplet with a volume of $0.1 \mathrm{~mm}^{3}$ has a radius of $\mathrm{r}=288 \mu \mathrm{m}$; this gives an idea of the range of capillary diameters that might be of interest. Of course, enough energy must be imparted to the slug of fluid in the capillary so that it is ejected far enough to overcome the surface tension, and so that the droplet may break free and have a useful free velocity. 
It is interesting to estimate the strain in a membrane of thickness, $\mathrm{T}_{\mathrm{m}}$, for very shallow deformations, similar to the preceding example. By approximating the deformed membrane in a simple two-dimensional circular arc segment, a rough estimate for the geometrical strain in the surface of the membrane can be obtained. First, the relations of the parameters of a circular arc are derived with the aid of Figure 5.2:



Figure 5.2. A segment of a circular arc is used to obtain a relation between the deflection, $\mathrm{h}$, the radius, and the diameter, $\mathrm{L}$, of the chord; this approximates a two dimensional membrane deflection.

$$
\begin{aligned}
& (\mathrm{L} / 2)^{2}+(\mathrm{r}-\mathrm{h})^{2}=\mathrm{r}^{2} \\
& \mathrm{r}=\left(\mathrm{L}^{2} / 4+\mathrm{h}^{2}\right) / 2 \mathrm{~h} \approx \mathrm{L}^{2} / 8 \mathrm{~h} \\
& \tan \Omega=(\mathrm{L} / 2) /(\mathrm{r}-\mathrm{h}) \approx 4 \mathrm{~h} / \mathrm{L} 5.13
\end{aligned}
$$

Again, considering some practical parameters, for $\mathrm{L}=1 \mathrm{~cm}$, and for $\mathrm{h}=2 \mu \mathrm{m}$, these expressions yield $\mathrm{r}=6.25 \mathrm{~m}$, and $\Omega=8 \mathrm{E}-4$ radians $=0.0458$ degrees. By considering a finite thickness, $\mathrm{T}_{\mathrm{m}}$, membrane that is deformed two dimensionally, like Figure 5.2, the top surface will be in tension and the bottom surface will be in compression. By considering the difference in 
arc lengths around a neutral arc, a simple estimate for the geometrical strain, $\mathrm{S}_{\mathrm{g}}$, at the surfaces can be derived using the radii at $\mathrm{r}_{\mathrm{i}, \mathrm{o}}=\mathrm{r} \pm \mathrm{T}_{\mathrm{m}} / 2$ and the equation 5.12:

$$
\mathrm{S}_{\mathrm{g}}=\left(\mathrm{T}_{\mathrm{m}} / 2\right) / \mathrm{r}=4 \mathrm{~h} \mathrm{~T}_{\mathrm{m}} / \mathrm{L}^{2}
$$

Using the previous parameters and a membrane thickness of $\mathrm{T}_{\mathrm{m}}=400 \mu \mathrm{m}$, which is approximately the thickness of the PZT bimorph, the geometrical strain is estimated by equation 5.14 to be $S_{\mathrm{g}}=3.2 \mathrm{E}-5$ for a deflection of $2 \mu \mathrm{m}$. Using the previous expressions for the piezoelectrically induced strain, equations 5.4, 5.6, with the same electric field, the piezoelectrically induced strain in the plane of the membrane is $\mathrm{S}_{\mathrm{p}}=9.0 \mathrm{E}-5$, which is comparable to the geometrical strain, $\mathrm{Sg}$, in magnitude. So it seems reasonable that the piezoelectric bimorph actuator is strong enough to deform itself to a sufficient extent to form $0.1 \mathrm{~mm}^{3}$ sized fluid well deformations, with free standing boundary conditions and using these simple order of magnitude approximations. Practical applied fields for the PZT can easily be an order of magnitude larger than those used in these estimates. The additional constraints imposed by the boundary conditions at the edge of the actuator membrane are expected to reduce the deflection estimates in these simple estimates. The exact solution of the coupled electromechanical equations is very difficult and probably not possible in closed form for this device, but it is not really necessary for a first phase design effort. In general, the stored energy in the mechanical terms will dominate the solution. The solutions for pure mechanical plates[3] will provide very good starting points for estimating the design parameters. In other words, the plate stiffness constant is modified only slightly by the presence of the piezoelectric effect; the electromechanical coupling coefficient is small. The exact circular plate theory[3] for both free and fixed boundary conditions will be used later for comparison to the experimental deflection measurements, but the simple estimates are seen to be useful.

\section{PZT Cantilever Bimorph Measurements}

The first tests done with the PZT bimorphs used a long narrow cantilever, supported like a diving board as described under PZT processing, step number 4, and as shown in Figure 5.3.

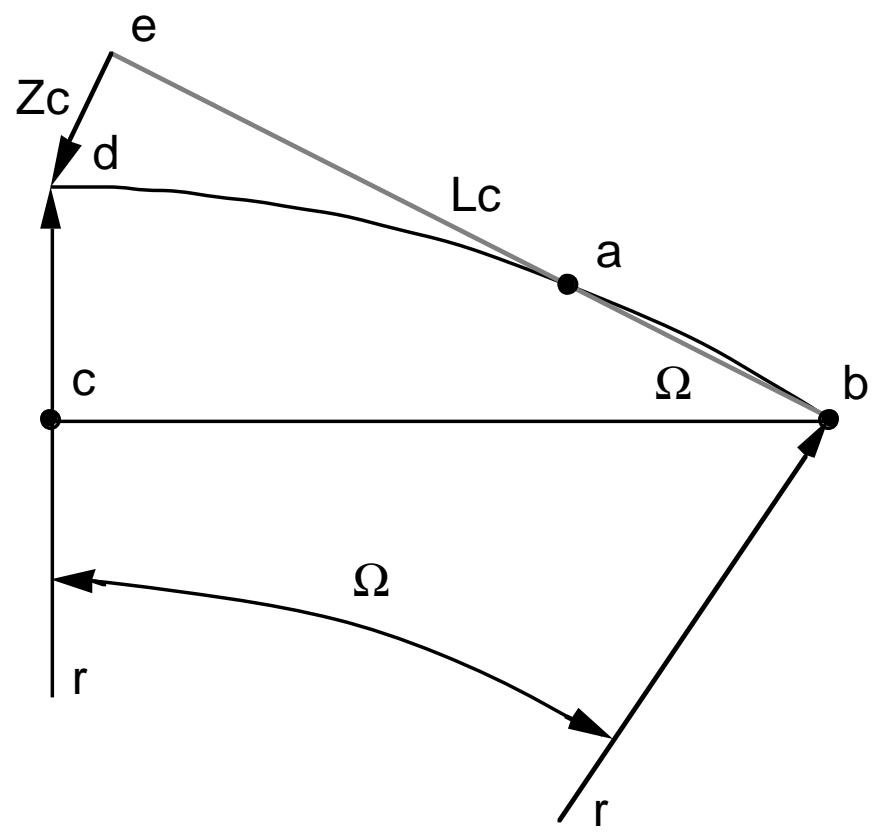


Figure 5.3. The PZT cantilever deflection is tested with an anchor at point $b$ and a fulcrum point at point a; the free end of the beam is at point e.

The length of the beam is Lc. The free end deflects in a motion shown as Zc under an applied bias. The bent beam is shown approximately in the shape of a circular arc. Experimentally, points $a$ and $b$ are close compared to Lc and also the angle abc is very small; the motion $\mathrm{Zc}$ is very small compared to the beam length, Lc. The motion Zc is very nearly vertical; it is viewed under a microscope.

The experimental configuration shown in Figure 5.3 was used to take deflection data for a bimorph cantilever and the free end deflection is shown in Figure 5.4 as function of bias voltage.



Figure 5.4. Deflection data for the free end of a PZT bimorph cantilever, $24 \times 1 \times 0.4 \mathrm{~mm}$. The fulcrum point is about $1.5 \mathrm{~mm}$ from the fixed end. The voltage is applied across the smallest dimension( $0.4 \mathrm{~mm})$.

The data of Figure 5.4 shows some hysteresis. The data is essentially static with about 20 seconds spent at each point to focus and read the microscope $\mathrm{Z}$ position, and then adjust the bias. The data shows that with the voltage returned to zero, the deflection also eventually relaxes back to zero, but there is a fast component of mechanical response to voltage and a smaller slow component that may last many minutes. The data also shows some inflections at 100 to $90 \mathrm{~V}$ transitions and 200 to 190 $\mathrm{V}$ transitions when the bias is decreasing. These transitions appear to be an artifact of the combination of hysteresis and the nature of the power supply that was adjusted with thumbwheel dials for $10 \mathrm{~V}$ and $100 \mathrm{~V}$ increments. It is not obvious why the bias step discontinuity appears only with decreasing bias curve and not on the increasing bias curve, since the upward bias involves a discontinuity as the bias sequence is $\ldots 70,80,90,0,100,110,120, \ldots$.etc. This data indicates that deflections large enough to be useful for fluid actuators should be possible with these type of components with practical voltages. Of course, the effects of other mechanical boundary conditions and the forces required to additionally deflect a smaller amount of silicon are expected to substantially affect the details. Square plates will be stiffer than slender cantilevers and fixed edge boundary conditions versus free ones will reduce the amount of motion. It is interesting to consider 
the amount of deflection, i.e. the amount of arching, $\mathrm{H}$, away from a straight line connecting the two ends, in the center of the bent bimorph as a function of the deflection of the free end which is more easily measured. This is illustrated with the use of Figure 5.5.

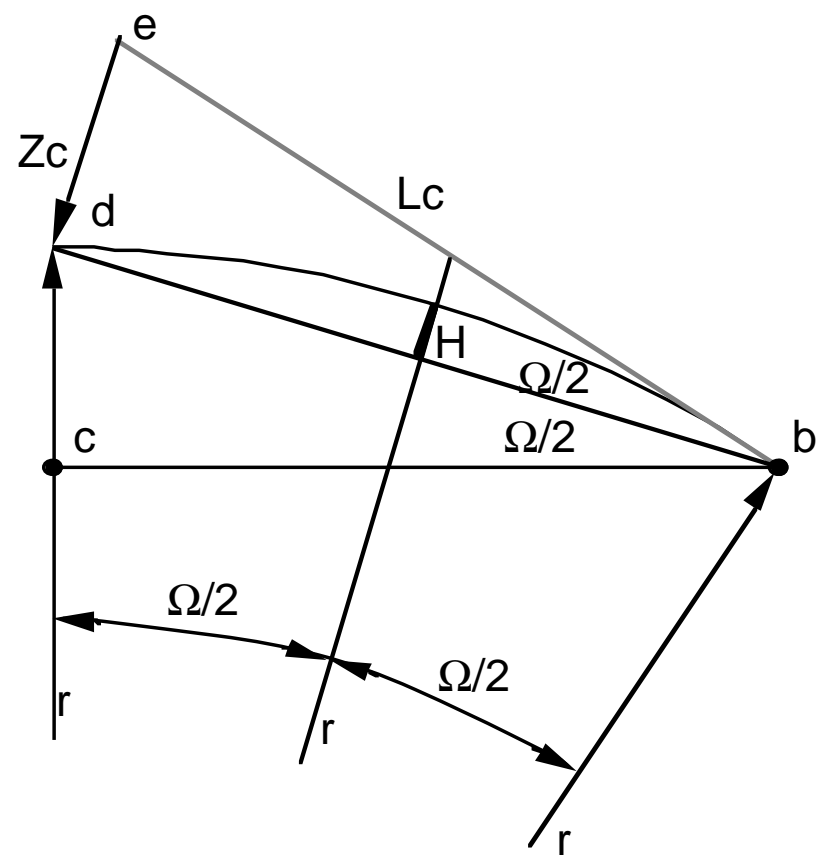

Figure 5.5. The bent cantilever is shown between points $\mathrm{d}$ and $\mathrm{b}$. The measured end displacement is labeled Zc. The limit case is considered for very small deflections Zc $<<$ Lc and also for very small angles $\Omega$. Zc is approximately vertical. The fulcrum point is approximated as being vanishingly close to point $b$, so that the initial cantilever is tangential at point $b$.

The approximations of a circular arc combined with the other assumptions allow an estimate for the amount of arching, $\mathrm{H}$, of the bimorph as a function of the free end deflection. From geometrical arguments and using the approximations derived from Figure 5.2 it can be shown that:

$$
\mathrm{H} \approx \mathrm{Zc} / 4
$$

As will be seen in the application of the bimorphs, the useful deflection of interest will be characterized by the center arching, $\mathrm{H}$, and this is seen to be smaller by about a factor of four(5.15) than the conveniently measured endpoint shown, for example, in the data of Figure 5.4.

The cantilever bimorph was also studied using a small signal sinusoidal source of variable frequency. This ac response of the cantilever free end, from a side view, was filmed on video, along with the step function response to various dc voltage steps. The dc voltage steps were as ideal as possible by precharging the dc supply and $50 \mathrm{ohm}$ supply line to the desired bias and then connecting it directly through a coaxial connector to the PZT. The step function responses showed similar behavior to that plotted in Figure 5.4, although with lesser precision; the hysteresis and fast/slow response attributes were clearly visible. The hysteresis and lag back to zero were evident in both polarities of step functions. The small signal ac response showed a series of mechanical resonances, as expected from the theory[4]. The resonances displayed a non-linearity that can be attributed to small nonlinear terms in the stress-strain relations. The qualitative behavior of the amplitude of vibration as a function of a slowly swept frequency is shown in Figure 5.6. 
16.


Figure 5.6a,b. The qualitative(from a side view video) swept frequency response of a bimorph cantilever. In figure a, the frequency is sweeping slowly up on the dashed line, and down on the solid line. The amplitudes of the resonances are lower in amplitude and higher in frequency for the upward sweep. In figure b, the characteristic theoretical shape of a nonlinear resonance is illustrated. The dashed line is not realized; the swept behavior follows the solid lines, which is consistent with the observations of figure a.

\section{PZT Square Plate Measurements and Theory}

A square bimorph plate of PZT similar to that planned for use in the fluidic drop transducer was built with $12 \times 12 \times 0.4 \mathrm{~mm}$ dimensions. This plate was first tested similar to the cantilever with one corner clamped, in a fulcrum style, and the other diagonal corner viewed under a microscope; this gives about two micron precision in the vertical deflection. The results are shown in Figure 5.7.

The deflection for the square bimorph is about $60 \mu \mathrm{m}$ at $250 \mathrm{~V}$, whereas for the longer cantilever beam of Figure 5.4, the deflection is about $200 \mu \mathrm{m}$ at $250 \mathrm{~V}$. Part of the larger deflection of the slender cantilever is certainly attributed to its greater length, but part of this is also from the lower stiffness of the cantilever structure. The bimorph of Figure 5.7 is designed to be used over silicon membranes that are $10 \times 10 \times 0.040 \mathrm{~mm}$, so that the bimorph is firmly bound at the edges with a $1 \mathrm{~mm}$ overlap onto the very rigid silicon frame. The deformation of the free square bimorph is very complex but a sketch of the expected deformation shape is shown in Figure 5.8. It is seen that the free square bimorph will tend to contract inward from the original square shape, shown in dashed lines, and that the deformation is complex. It is easy to envision with the aid of Figure 5.8, that if the edges of the square bimorph are rigidly clamped, as they are in the actual chemjet device, the edge boundary conditions become extremely complex. They are not only restrained from shrinking laterally, but the angle at the edges must tend toward a flat tangential boundary condition; also, although the silicon wafer provides a very rigid frame to support its own membrane and the bimorph, some distortion is expected to occur in it too. 
17.

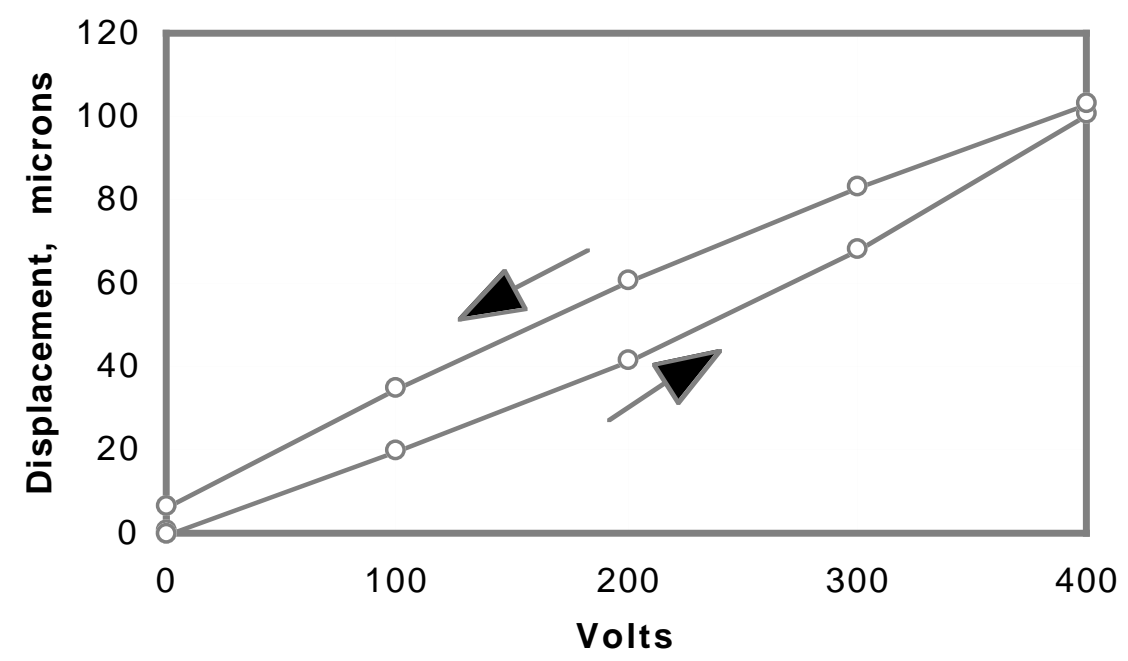

Figure 5.7. Deflection data for a square PZT bimorph, $12 \times 12 \times 0.4 \mathrm{~mm}$. The deflection is measured on a corner diagonally opposite the clamped corner.

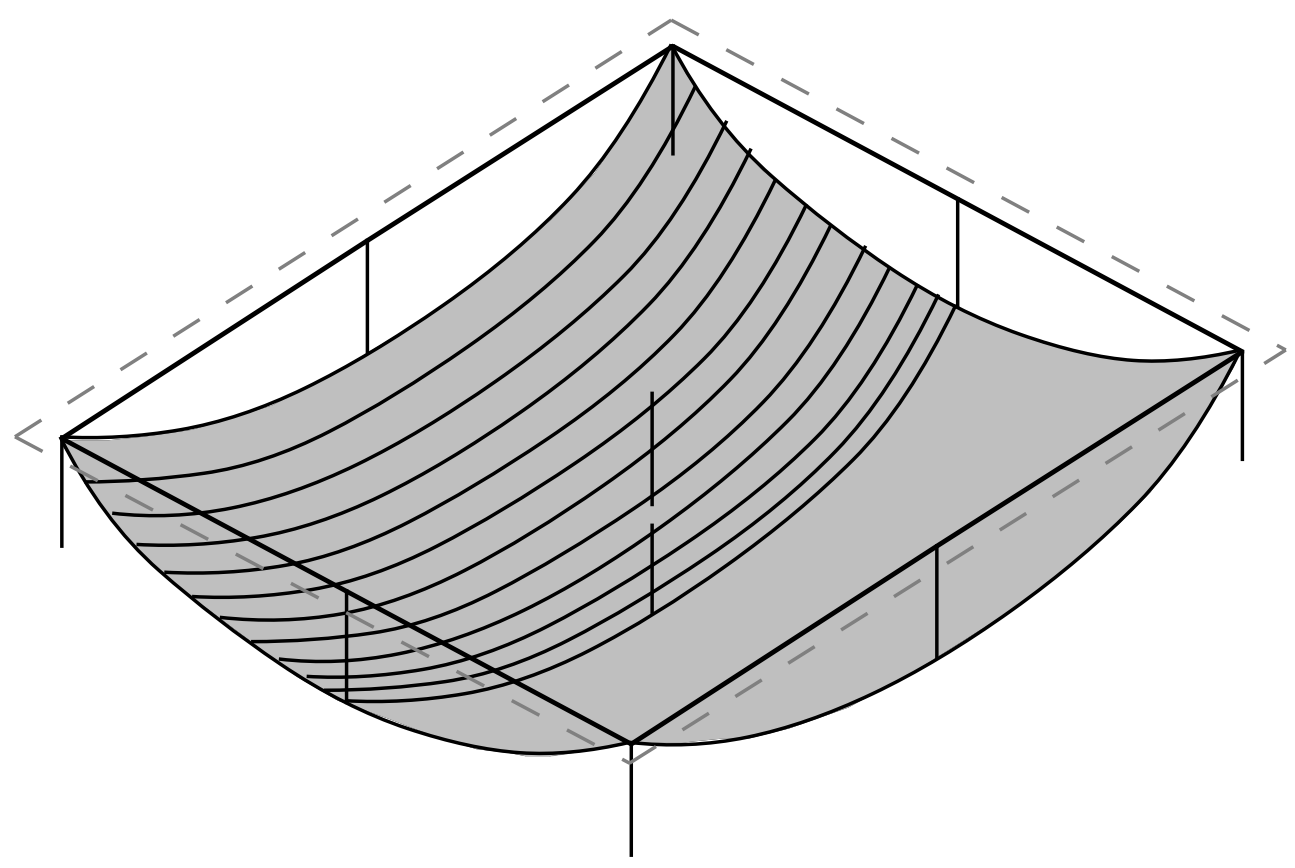

Figure 5.8 The deformation of a free standing biased square bimorph is shown as a sketch, that shows the lateral contraction, as well as the compound curvature. The original square shape is shown as the dashed line. This shape is off the type measured in Figure 5.7. 
The actual PZT/silicon composite actuator, as used and mounted on the prototype chemical jet device, was tested on a sample silicon wafer without the Pyrex capillary plate. The initial composite actuator testing was done without the Pyrex to enable an optical profilometer head to enter the well region of the silicon and measure the deflection of the composite membrane as a function of the PZT bias. The results are shown in Figure 5.9. Compared to the free bimorph plate deflections, the deflection is significantly reduced by the additional stiffness imposed by the silicon, the silicon frame mounting boundary conditions, the increased rigidity caused by the edge seal epoxy and the mounting epoxy, and the top contact epoxy. The free bimorph of Fig. 5.7 has a center deflection of about $(100 \mu \mathrm{m}) / 4=25 \mu \mathrm{m}$ at $400 \mathrm{~V}$; the composite actuator of Figure 5.9 has a center deflection of about $14 \mu \mathrm{m}$ at $400 \mathrm{~V}$. However, this final deflection is almost ten times what is estimated to be required to compress the fluid well enough to form microdroplets, if no other losses are incurred.

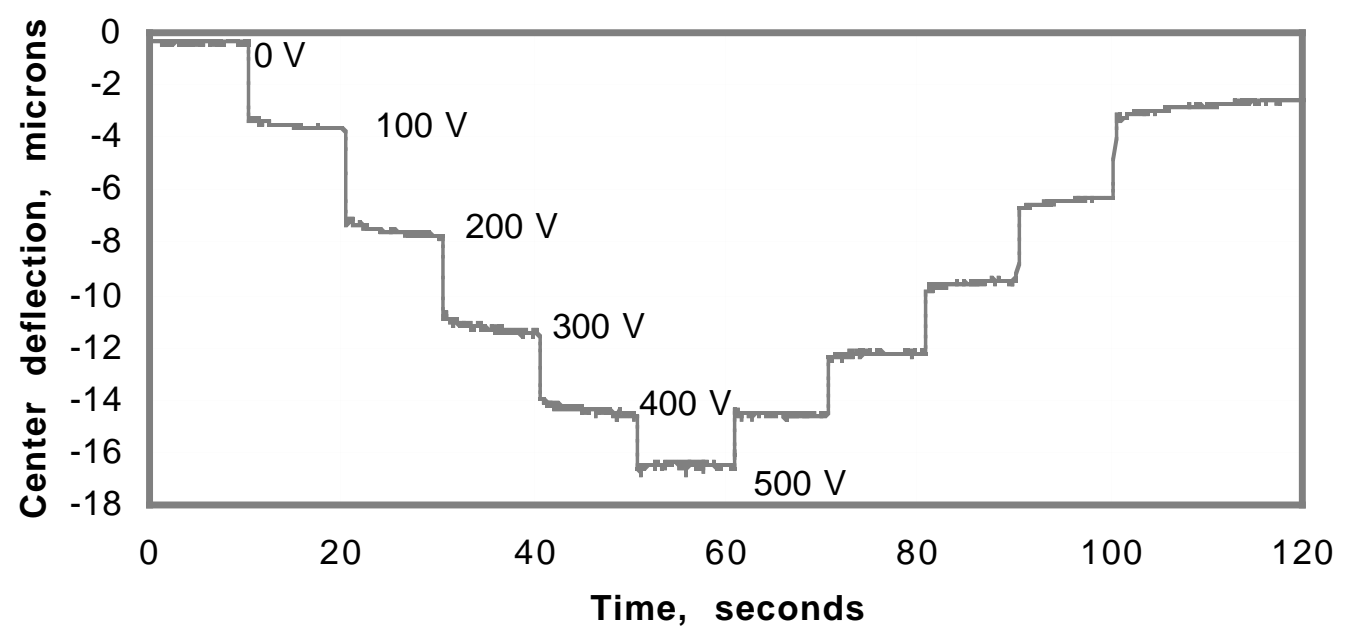

Figure 5.9. PZT/silicon composite actuator deflection. The PZT bimorph is $12 \mathrm{x} 12 \mathrm{x} 0.4 \mathrm{~mm}$. The silicon membrane is $10 \times 10 \times 0.040 \mathrm{~mm}$; the silicon membrane wafer frame is $0.375 \mathrm{~mm}$ thick. The Pyrex substrate is not included.

A sketch, to scale, of the cross section of the composite actuator mounted on the silicon/Pyrex substrate is shown in Figure 5.10. Even though the silicon is about twice as strong as the PZT, it is so thin relatively, that it approximately comforms to the deflection imposed by the PZT. It is obvious that there are so many design variations and parameters, that an optimal design is not readily apparent. Two very critical parameters are the length to thickness ratio of the PZT, and thickness ratio of the PZT to silicon. Considering just the boundary conditions of the PZT plates yields many possibilities. The amount of PZT overlap(if any) onto the silicon is one major parameter. The one millimeter amount chosen in Figure 5.10 is estimated to be enough to give a strong edge mount that will resist accidental bursting during priming operations, but not so much that the PZT deformation is impeded in a major way. This mounting format with the edge angular restraint and lateral restraint, tends to restrict the vertical deflection significantly as the plate theory will indicate, but serves to be a conservative practical approach. 
19.

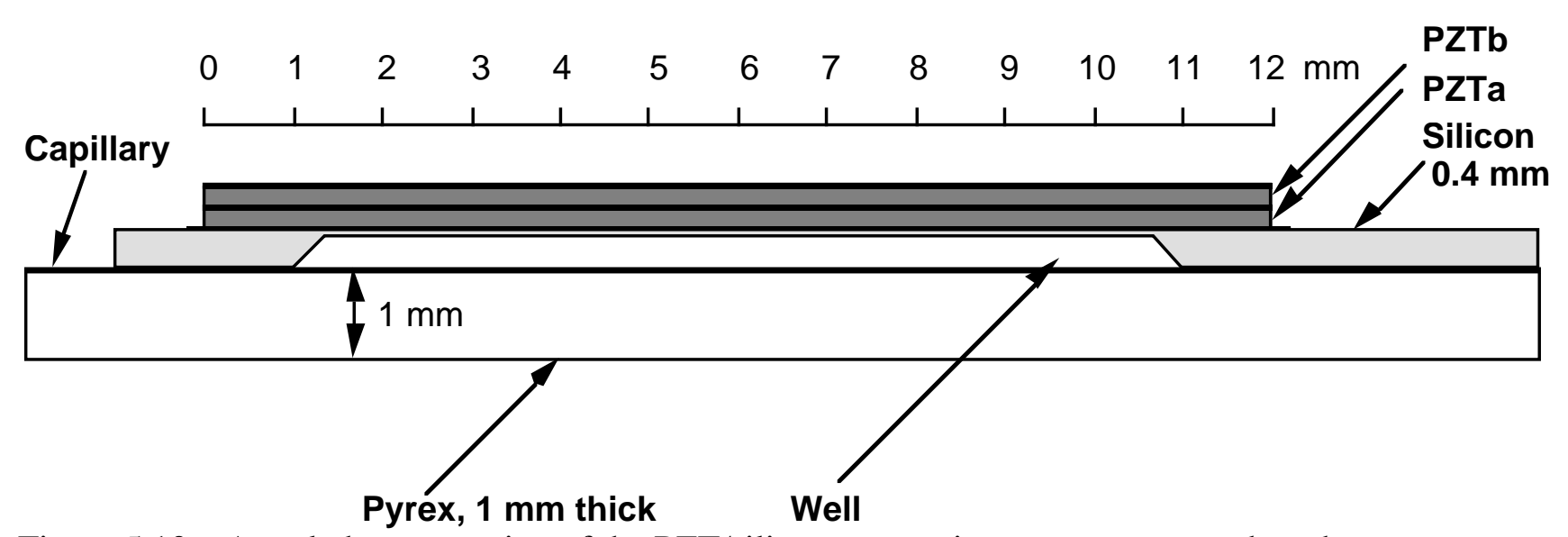

Figure 5.10. A scaled cross section of the PZT/silicon composite actuator mounted on the silicon/Pyrex bonded substrate. The PZT bimorph is $12 \times 12 \times 0.4 \mathrm{~mm}$. The silicon membrane is $10 \times 10 \times 0.040 \mathrm{~mm}$; the silicon membrane wafer frame is $0.375 \mathrm{~mm}$ thick, and the Pyrex is $1 \mathrm{~mm}$ thick. The PZT mounting epoxy is shown approximately to scale as a heavy black line. The edge sealing epoxy around the PZT bimorph and the top wire epoxy connection are not shown.

The composite actuator deflection shown in Figure 5.9 is, of course driven by piezoelectric effect. This effect causes the differential shrinkage and expansion of the PZT layers which causes the composite plate deformation. It is interesting to estimate what kind of comparable mechanical force will cause a similar deflection. This can be done by using existing thick plate theory from the literature[3]. The theory that will be adapted to this problem is that of thick homogeneous circular plates subjected to small deflections. In adapting the mechanical plate theory, the induced piezoelectric effect will be neglected since it is a small second order effect(floating electrodes and no applied field), compared to the large mechanical driving force applied. In other words, the stored energy of the applied mechanical fields is much greater than the stored energy of the induced piezoelectric fields, or the electromechanical coupling coefficient is small.

The theory for the thick homogeneous plate where the plate thickness is no more than one fourth the radius and the deflection is less than half the plate thickness gives the following formulas for the rigid plate edge boundary condition. The rigid, fixed edge, boundary condition allows no perpendicular motion and no angular deflection at the plate edge.

$$
\begin{aligned}
& \mathrm{h}=\mathrm{Pa}^{4} / 64 \mathrm{D} \\
& \mathrm{D}=\mathrm{Et}^{3} / 12\left(1-\mathrm{pr}^{2}\right) \\
& \mathrm{y} / \mathrm{h}=-1+2(\mathrm{r} / \mathrm{a})^{2}-(\mathrm{r} / \mathrm{a})^{4}
\end{aligned}
$$

The deflection at the center of the plate is $\mathrm{h}$, the applied pressure is $\mathrm{P}$, the radius is a, the plate stiffness constant is D, the Young's modulus is E, the plate thickness is t, the Poisson's ratio is $\mathrm{pr}$. The vertical deflecton of the plate is given by equation 5.18 , where the normalized vertical deflection is $\mathrm{y} / \mathrm{h}$ and the normalized radius is (r/a) and this curve(fixed edge) is plotted in Figure 5.11. 
20.

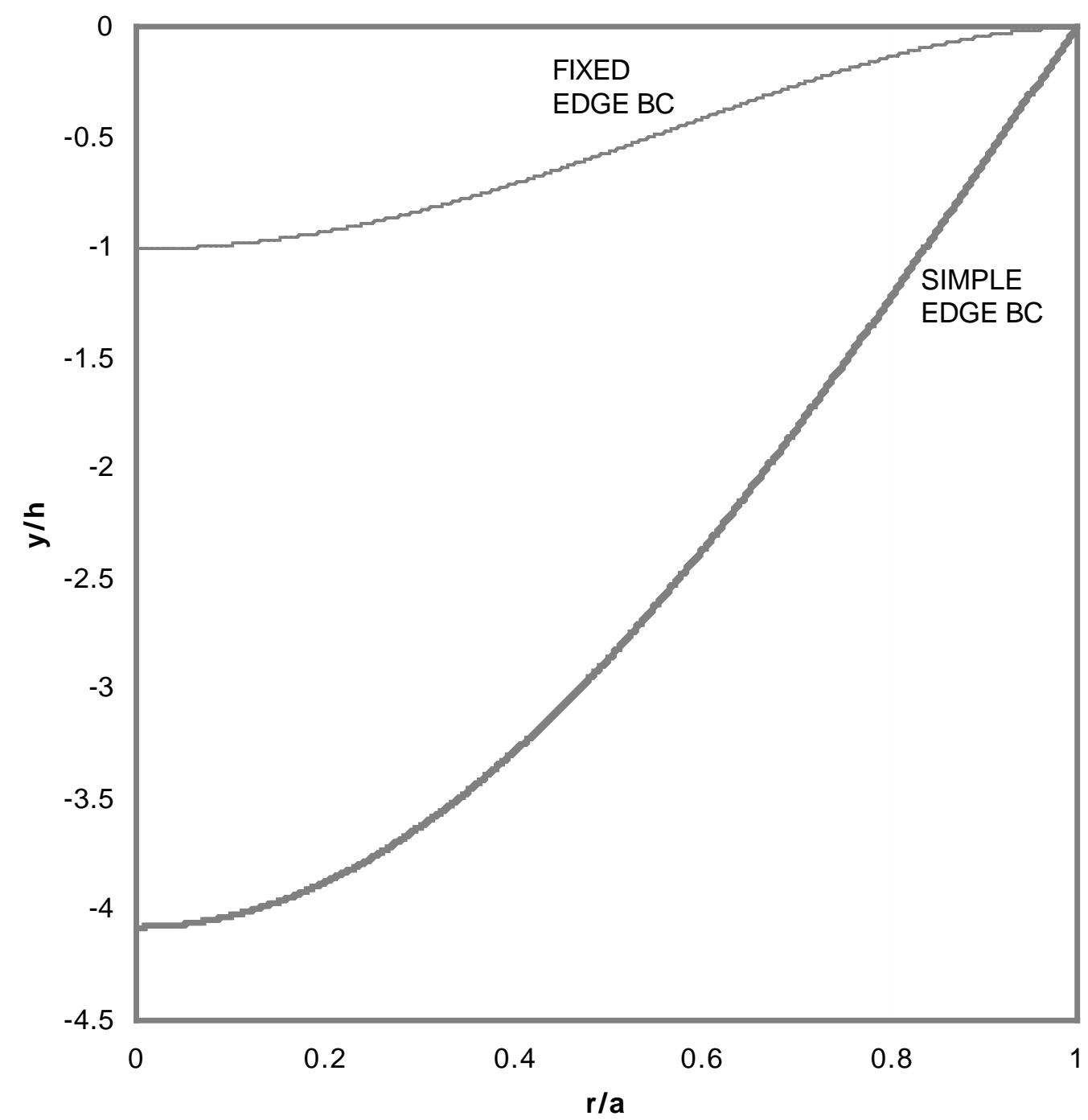

Figure 5.11. The normalized deflection profiles for a thick circular plate of radius a and thickness $t$ are shown where the center deflection is normalized by $h($ eqn. 5.16); the theory requires $h<t / 2$ and $\mathrm{t}<\mathrm{a} / 4$. The plate is restrained by fixed or simple boundary conditions at the edge, $\mathrm{r}=\mathrm{a}$, and $\mathrm{a}$ vertical pressure is applied.

The composite actuator plate is composed of several materials which will be replaced by an equivalent amount of PZT with some assumptions for the purposes of theoretical estimates. The actual plate has a thickness, texp:

$$
t_{\exp }=\mathrm{t}_{\mathrm{pzt}}+\mathrm{t}_{\mathrm{ep}}+\mathrm{t}_{\mathrm{si}}=600 \mu \mathrm{m}
$$

where $\mathrm{t}_{\mathrm{pzt}}=457 \mu \mathrm{m}$ of PZT, $\mathrm{t}_{\mathrm{ep}}=102 \mu \mathrm{m}$ of epoxy, and $\mathrm{t}_{\mathrm{si}}=41 \mu \mathrm{m}$ of silicon. It is assumed that the epoxy will have the same Young's modulus as the PZT. The silicon will be 
replaced by a slightly thicker equivalent of PZT. This can be done by replacing the silicon with PZT such that this plate layer stiffness constant remains unchanged. Since the Young's modulus of PZT is less than silicon, the effective layer thickness will increase slightly from $41 \mu \mathrm{m}$ of silicon to $55 \mu \mathrm{m}$ of PZT. The square diaphragm of $10 \mathrm{~mm}$ of actuator is replaced by an equal area circle of radius $\mathrm{a}=5.64 \mathrm{~mm}$.

The following material constants are used in subsequent plate theories:

\begin{tabular}{|l|l|l|l|l|l|l|}
\hline & $\mathrm{c} 11$ & $\mathrm{c} 12$ & $\mathrm{c} 44$ & Poisson's & density & Young's mod \\
\hline & $\mathrm{GPa}$ & $\mathrm{GPa}$ & $\mathrm{GPa}$ & ratio, $\mathrm{pr}$ & $\mathrm{g} / \mathrm{cm}^{3}$ & $\mathrm{GPa}$ \\
\hline \hline Silicon & 166 & 63.9 & 79.6 & $0.28[001]$ & 2.33 & $130.5[100]$ \\
\hline & & & & & & $169.1[110]$ \\
\hline & & & & $0.18[110]$ & & $187.9[111]$ \\
\hline Germanium & 128 & 48.3 & 68 & 0.27 & 5.32 & $101.5[100]$ \\
\hline GaAs & 119 & 53.8 & 59.5 & 0.31 & 5.32 & $85.5[100]$ \\
\hline PZT & & & & 0.3 & 7.5 & $61.0[11]$ \\
\hline & & & & & & $53.2[33]$ \\
\hline
\end{tabular}

Table 5.2. Some useful material constants including the elastic moduli, Poisson's ratio, density, and Young's moduli.

The parameters needed to estimate the pressure that would cause the deflection of $16 \mu \mathrm{m}$ observed in Figure 5.9 are now established, and will be used in equations 5.16 and 5.17, which are combined and rewritten in terms of pressure, $P_{t p}$ for the thick plate:

$$
P_{t p}=(16 / 3)\left(E_{t}^{3} h /\left[a^{4}\left\{1-p_{r} 2\right\}\right]\right)
$$

With, $\mathrm{E}=53.2 \mathrm{GPa}, \mathrm{t}=614 \mu \mathrm{m}, \mathrm{h}=16 \mu \mathrm{m}, \mathrm{a}=5.64 \mathrm{~mm}$, and $\mathrm{pr}=0.3$, equation 5.20 for the pressure required to induce the deflection, $h$, yields $\mathrm{P}_{t p}=1.14 \mathrm{MPa}(166 \mathrm{psi})$, an experimentally high and useful pressure value.

It is helpful to establish some validity for the approach used above by considering separate experimental data[5] obtained for octagonal pure silicon membranes and applying equation 5.20. The pure silicon plate has a radius of $\mathrm{a}=2 \mathrm{~mm}$, and a thickness of $\mathrm{t}=50 \mu \mathrm{m}$. This plate has been experimentally observed to produce deflections of about $50 \mu \mathrm{m}$ with pressures of about $0.34 \mathrm{MPa}(50 \mathrm{psi})$; these values are well below failure values. With a deflection equal to the plate thickness, this situation slightly exceeds the formula constraints for small deflections $(h<t / 2)$, but the errors are not expected to be enormous. For this simple silicon plate, equation 5.20 yields a required pressure of $\mathrm{P}_{\mathrm{tp}}(\mathrm{si})=0.3 \mathrm{MPa}(43 \mathrm{psi})$, which is in reasonably good agreement with the experiment(50 psi).

It is important to note that the rigid boundary conditions for thick plate theory apply; namely that the no angular deflection is allowed at the edge of the plate. If this angular constraint is removed, the theory shows that the deflection of equation 5.16 is increased by a factor of $(5+\mathrm{pr}) /(1+\mathrm{pr})$, which is approximately a factor of four, as shown in Figure 5.11. In other words, the plate becomes less stiff by this amount. However, this should not be confused with the situation for thin shells. Many thin shell and beam theories exist, including one for square thin shells[6-9]. The key point is that the former theory that is relevant to the PZT actuator is a thick plate small deflection theory 
$(h<t / 2$, and $t<a / 4)$. The thin shell theory is very useful for very thin membranes of silicon and silicon nitride and this theory assumes the deflections are large and membrane is very thin $(\mathrm{h} \gg \mathrm{t}$, and $\mathrm{t} \ll \mathrm{a})$. Often, the angular boundary condition at the edge is assumed to be free. Even if it is not, major changes do not occur in deflection for the shell. An example of thin shell deflection theory shows the dramatic difference in dependence of the main variables[6]:

$$
P_{S}=(8 / 3)\left(E t^{3} /\left[a^{4}\{1-0.24 \operatorname{pr}\}\right]\right)
$$

Notice that the main differences are the pressure is proportional to $\mathrm{t}^{3} \mathrm{~h}$ for the thick plate theory(eqn. 5.20) and to $t^{3}$ for the shell theory(eqn. 5.21). These different regimes are very important to consider when designing the actuators for the chemical jet drive actuator. 


\section{Microfluidic Theory and Measurements}

\section{Introduction and capillary flow theory}

The initial testing of capillary channels in the bonded silicon Pyrex wafer pair was done using water with the intent to see if the flow rates were visible and reasonable and that delamination and blockage did not occur. Simple theory[10] of capillary flow may be used to estimate the flow rates. The flow rate is given by:

$$
\mathrm{F}=\left(\pi \mathrm{P} \mathrm{R}_{\mathrm{C}}^{4}\right) /\left(8 \mathrm{l}_{\mathrm{c}} \mathrm{V}\right)
$$

where $\mathrm{F}$ is the flow rate, $\mathrm{P}$ is the pressure drop across the capillary, $\mathrm{R}_{\mathrm{C}}$ is the radius of the capillary, $l_{\mathrm{C}}$ is the length of the capillary, and $\mathrm{V}$ is the viscosity of the fluid. Several flow rates are computed for convenience in the table shown below.

\begin{tabular}{|c|c|}
\hline $\mathbf{R}_{\mathbf{c}}$, capillary radius & F, flow rate \\
\hline micrometers & $\mathbf{m m}^{\mathbf{3}}$ / $\mathbf{~ s e c}$ \\
\hline \hline 10 & 0.0271 \\
\hline 20 & 0.433 \\
\hline 40 & 6.932 \\
\hline 80 & 110.9 \\
\hline 100 & 270.8 \\
\hline 120 & 561.5 \\
\hline 140 & 1040.3 \\
\hline 200 & 4332.8 \\
\hline 300 & 21934.8 \\
\hline
\end{tabular}

Table 6.1. Flow rates for capillaries assuming a pressure of $0.6895 \mathrm{MPa}(100 \mathrm{psi})$, a length of $10 \mathrm{~cm}$, and a viscosity of $1 \mathrm{mPa}-\mathrm{sec}(1 \mathrm{cp})$ for water.

\section{Initial large capillary flow tests}

The first flow tests made on bonded substrate pairs had capillaries with a trapezoidal etched cross section and an equivalent radius equal to about 80 micrometers. The dead well and driven well regions of the silicon, where the silicon membrane is thin, was manually capped with a glass blank plate held in place with hand pressure. Pressurized water up to about $0.2 \mathrm{MPa}$ (30 psi) was introduced into the inlet ports with a flexible vinyl tubing and the resulting water streams from the exit capillaries were seen to emerge about $20 \mathrm{~cm}$. This proved to be a quick test that showed the flow rate was about right and that the substrate bonding was adequate. However, it proved to be very difficult to hold the glass blanking plate down with sufficient pressure to avoid rupturing or cracking the silicon well membranes, even with modest water pressures. In these initial tests, the water flow seemed to purge the flow channel clean of any trapped air. 


\section{Initial small capillary flow tests}

The first tests with smaller capillaries used the etched trapezoidal cross section capillaries again, with much smaller equivalent radii of about 20 micrometers; the silicon well regions were capped over with glass blanks that were epoxied directly onto the dead well regions. The driven well regions were capped with the composite PZT bimorph. During the final precision cut of the bonded substrate pair to form the exit capillary nozzles, there was concern that particles from the water cooled saw would wick up into the capillaries and block them. Wicking of several cubic millimeters of fluid was observed into the driven well, but this did not block the capillaries.

A syringe was attached with epoxy to the silicon substrate using a supporting aluminum ferrule about $4 \mathrm{~mm}$ in diameter. Gluing technique was important so as not to block the capillary path; this is described in Section IV, Bonding and Final Assembly. The first tests with small capillaries showed that small air bubble were trapped in both the dead well and driven well; much more trapped air was observed in the driven well. Using the air head in the syringe body as a simple pressure gauge, pressures up to about $1 \mathrm{MPa}$ (130 psi) were applied. The flow from the exit capillaries was very small, on the order of one $\mathrm{mm}^{3}$ / sec or less. Soap solutions and isopropyl alcohol fluids were also tried, usually followed by very long water flush. Nothing seemed to avoid the formation of trapped air bubbles in the driven well region. The bubbles appeared to form in random locations and were mostly in the 0.05 to $0.5 \mathrm{~mm}$ size range. The visual shrinkage of the bubbles in response to high inlet pressures gives estimates of the pressure developed in the wells. On a few occasions, by changing the orientation of the device dynamically, a bubble in the water was seen to traverse the exit capillary portion of the driven well while this exit capillary was oriented mostly vertically. The captured bubble was able to move across the upside down "drain hole" without getting sucked out. Apparently, the force needed to deform and pull the bubble into the exit channel, and overcome its surface tension, was insufficient; the flow and pressure - up to about $1 \mathrm{MPa}(130 \mathrm{psi})$ at the inlet were not adequate. Although reasonable steady state flow in these tests was obtained, the trapped air bubbles in the driven well region of the device prevented the PZT actuator from ejecting any water droplets. Clearly, the fast compressive action of the PZT was absorbed in the driven well air bubbles.

\section{Second large capillary flow tests}

The third series of fluid flow tests used devices with large capillaries again, about 120 micrometers in diameter, but these tests used the syringe input and glass blanks and PZT bimorphs in a fully assembled device. Again, bubbles were trapped in the driven well of the device very easily when water was used to prime the channel, but the problem was reduced by about an order of magnitude by changing the purge technique. By initially purging with isopropyl alcohol, and then switching to water gradually at the inlet, it was possible to purge the device to where it appeared to be bubble free as long as flow was maintained. High pressure of about $0.5 \mathrm{MPa}(75 \mathrm{psi})$ produced fluid streams vertically up to about $40 \mathrm{~cm}$. Suck back of air into the exit nozzle during these tests was a problem. The small, $\sim 0.2 \mathrm{~mm}$ long, bubble stuck in the exit nozzle region was seen to move out and back with the application of single pulse to the PZT; this was the first demonstration of PZT induced fluid motion. The motion ranged from about $0.6 \mathrm{~mm}$ with $400 \mathrm{~V}$ for $50 \mathrm{~ms}$ down to about $0.2 \mathrm{~mm}$ with about $5 \mathrm{~ms}$ duration pulses. Subsequent testing showed that the water could be made to bulge in a dome like fashion from the exit nozzle; however, it did not break free from the surface tension and become fully ejected. The problem still appeared to be a result of very small trapped bubbles in the driven well region which absorbed almost all of the PZT energy and compressional motion. It is interesting to note that the trapped bubbles did not seem to form in the square corners of the driven well. The static estimates of the PZT deflection indicated that volume compression of the driven well 
chamber should be about an order of magnitude more the typical droplet size desired(comparable to the exit nozzle final diameter).

\section{Actuator micro droplet ejection measurements}

There was insufficient time to completely reprocess the device with the appropriate geometry and fabrication changes learned from the series of initial tests. However, some partially processed substrates, held in reserve, were modified for one final series of tests. For the final series of tests, some Pyrex substrates with etched channels were modified before bonding with a miniature hand held abrasive grinding wheel tool. The area of glass at the exit capillary groove of the driven well region was ground out and down, effectively widening and deepening the exit channel by several hundred micrometers; at the same time, the length of the original narrow exit capillary was reduced from $3 \mathrm{~mm}$ to $1 \mathrm{~mm}$. This enabled the purging pressure to dramatically increase the flow out of the driven well and remove all the large trapped bubbles. The ground surface was extremely rough and tended to trap some very, very small bubbles that were barely visible with a $15 \mathrm{X}$ magnifier. Still, the repeated alcohol merging to water method of purging resulted in a big improvement. The final trapezoidal shaped exit channel nozzles were about $100 \mu \mathrm{m}$ deep, and $200-250 \mu \mathrm{m}$ wide, and about $1 \mathrm{~mm}$ long.

Finally, the major goal of this project was achieved when $150 \mu \mathrm{m}$ diameter droplets were successfully, individually ejected from the nozzle with $700 \mathrm{~V} / 50 \mathrm{~ms}$ pulses. The PZT actuated droplets, one drop per pulse, were captured on a hydrophobic silicon wafer several $\mathrm{mm}$ away from the nozzle. The target wafer was displaced between drops manually. The visual inspection of the drops under $10 \mathrm{X}$ magnification appeared to indicate a very uniform size about $\pm 7 \%$. The drops evaporated in a few minutes under the laminar flow clean air bench.

\section{Conclusions}

A single channel of the micromachined chemical jet dispenser has been successfully demonstrated and a patent disclosure filed[11]. The final modifications to the device involved custom fabrication of the final channel on a bonded substrate pair that had six parallel channels available. By minor modifications of the fabrication procedure and some minor design changes, an array of similar chemical jet channels could be made, each with independent drive and fluid sources.

One big design improvement that is easily implemented would be to move the micro capillaries from the glass to the silicon. The surfaces would be much smoother and a combination of isotropic and anisotropic etching could be used with the addition of one masking layer to the silicon. The glass processing would be significantly reduced to a minimal value and it would simply serve as a capping and structural layer. The glass is not essential to the design concept, but is has been extremely useful to see through the glass and determine the operational pitfalls. The addition of a hydrophobic coating to the exit face of the nozzles would be useful.

Many interesting attributes and characterization remains to be done. These include characterizing the droplets speed and uniformity; refill and speed limitations; fluid feed control; minimum voltage and pulse length requirements; minimum transducer diameters required; and effect(if any) of the acoustic pressure wave on biological solutes such as live cells and DNA fragments. 


\section{References and Acknowledgments}

\section{References}

1. J. F. Nye, Physical Properties of Crystals: their Representation by Tensors and Matrices, 1957.

2. Transducer Products Inc., Specification Sheet Lead Titanate Zirconate - LTZ-2 type, Rt. 63 North, Goshen, Connecticut, 06756.

3. R. J. Roark and W. C. Young, Formulas for Stress and Strain, McGraw-Hill, 5th ed., 1975, pp. 332-363.

4. C. L. Lee, "Smart Fuzing Accelerometer Switch, Section C: The Linear Dynamics of a Microsensor Accelerometer Modeled as a Cantilever Beam with an End Mass", LLNL report UCRLID-103482-94, pp. 305-348.

5. J. F. Folta, LLNL Micro Technology Center, private communication.

6. M. K. Small and W. D. Nix, "Analysis of the accuracy of the bulge test in determining the mechanical properties of thin films", J. Mater. Res., v. 7, no. 6, June 1992, pp. 1553-1563.

7. R. I. Pratt and G. C. Johnson, "Mechanical Characterization of Thin Films Using Full-Field Measurement of Diaphragm Deflection", thesis University of California Berkeley, 1995.

8. T. S. Low and W. Guo, "Modeling of a Three Layer Piezoelectric Bimorph Beam with Hysteresis", J. Microelectromechanical Sys., v. 4, no. 4, Dec.1995, pp. 230-237.

9. D. Maier-Schneider, J. Maibach, E. Obermeier, "A New Analytical Solution for the Load Deflection of Square Membranes", J. Microelectromechanical Sys., v. 4, no. 4, Dec.1995, pp. 238241.

10. Handbook of Chemistry and Physics, CRC Press, 1961, Capillary Flow, p. 2209.

11. Patent Disclosure IL-9721, 3/23/95, "Micromachined Chemical Jet Dispenser", Steve P. Swierkowski. DOE file 4/13/95.

\section{Acknowledgments}

The author wishes to acknowledge the help and suggestions of his coworkers in the LLNL Micro Technology Center. In particular, co-author Dino Ciarlo provided a great deal of helpful fabrication and process equipment information. Conrad Yu provided instruction and CVD coating of silicon nitride. Chris Lee helped with cantilever measurements. Jim Folta provided additional silicon membrane deflection data to compare with and validate the theory. The many contributions and patience of the staff of the fabrication lab, including Julie Hamilton, Bill Benett, Norm Raley, Bill Goward, Randy Hicks, Holly Petersen, and Les Jones, is very much appreciated.

Critical review of the proposal and support of the LLNL LDRD committee, including Ray Mariella, Don T. Davis and Harry Robey has been instrumental in making this project possible. 


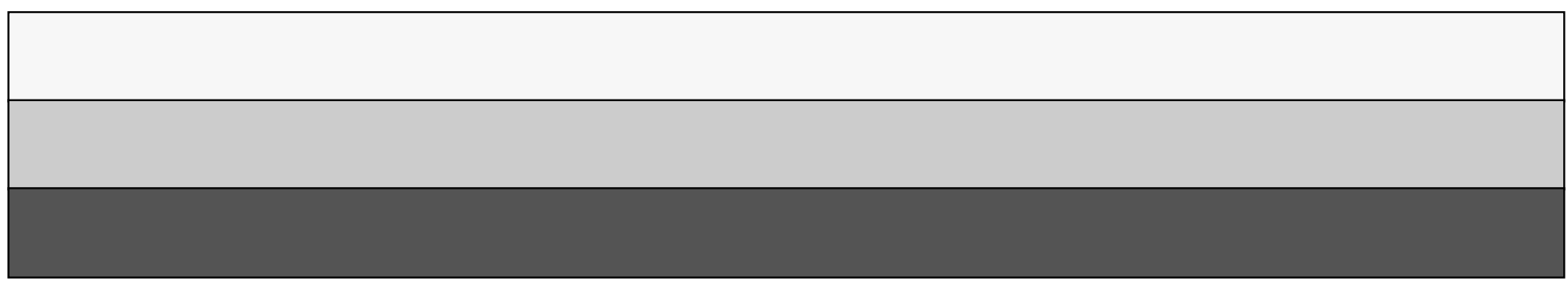

